\title{
Histopathological Spectrum of Breast Lesions - A Study Done in a Tertiary Care Hospital
}

\author{
Letha Padmom¹, Kiran Sapru², Devi Beena ${ }^{3}$ \\ ${ }^{1}$ Department of Pathology, Azeezia Institute of Medical Sciences and Research, Kollam, Kerala, India. \\ ${ }^{2}$ Department of Pathology, Azeezia Institute of Medical Sciences and Research, Kollam, Kerala, India. \\ ${ }^{3}$ Department of Pathology, Azeezia Institute of Medical Sciences and Research, Kollam, Kerala, India.
}

\section{ABSTRACT}

\section{BACKGROUND}

Breast cancer accounts for about one-third of female cancers and nearly about onefourth of all malignancies. Breast carcinoma, in India, is the second most common malignancy after carcinoma cervix. Well timed and precise detection of a lump in the breast and prompt intervention can reduce not only the concern but is also lifesaving in many. We wanted to study the histopathological spectrum and prevalence of breast lesions.

\section{METHODS}

This is a retrospective study done among 867 cases of breast lesions. The histopathological features were studied, and the various entities were diagnosed based on the WHO classification of tumours of the Breast.

\section{RESULTS}

Unilateral lesions (91.7\%) were much more common than bilateral lesions. Most of the cases were benign (88.3\%) of which the most common was fibroadenoma accounting for 496 (57\%) of all cases followed by fibroadenosis (16.26\%). Among the malignant cases the most common was invasive ductal carcinoma NOS accounting for 92 cases $(10.6 \%)$.

\section{CONCLUSIONS}

The pattern of breast lesions provides beneficial information concerning clinicopathological spectrum of breast lesions. For the correct and adequate treatment, clinical diagnosis, correlation and confirmation with the histopathological diagnosis of a breast lump is a must. Proper breast cancer awareness study and screening programs should be conducted across women of all status so that basic training and motivation can be given to women to report to the doctors as early as possible once a lump is noticed. This can reduce the morbidity and mortality associated with breast tumours.

\section{KEY WORDS}

Fibro Adenoma, DCIS, Ductal Carcinoma
Corresponding Author:

Kiran Sapru,

Assistant Professor,

Department of Pathology,

Azeezia Institute of Medical Sciences and

Research, Kollam, Kerala, India.

E-mail: kiransapru@gmail.com

DOI: $10.14260 / \mathrm{jemds} / 2020 / 308$

Financial or Other Competing Interests: None.

How to Cite This Article:

Padmom L, Sapru K, Beena D. Histopathological spectrum of breast lesions- a study done in a tertiary care hospital. J. Evolution Med. Dent. Sci. 2020;9(17):1412-1415,

$10.14260 /$ jemds $/ 2020 / 308$

Submission 18-10-2019,

Peer Review 03-02-2020,

Acceptance 11-02-2020,

Published 27-03-2020.

\section{(i)}




\section{BACKGROUND}

In India, the second most common malignancy after cervical carcinoma is carcinoma breast ${ }^{1}$ and is seen in $20 / 1,00,000$ women. ${ }^{2}$ Lesions of the breast are diverse including several entities with remarkably diverse characteristic features ${ }^{3}$ extending from inflammatory non-neoplastic and benign lesions to life threatening invasive carcinomas. ${ }^{4}$ World-wide breast lesions have become a major cause of mortality among women. ${ }^{5}$ Most of the breast lesions usually present as a lump or swelling in the breast which is a very sensitive matter for female patients because of which timely reporting to the doctor for an examination won't happen. ${ }^{6}$ Neoplasms of the breast are diversified. Malignant breast lesions are less common than benign tumours. Benign lesions of the breast usually present in the second decade of life. ${ }^{7}$ Common benign lesions of the breast include fibroadenoma, phyllodes tumour, lactating adenoma and tubular adenoma. Benign proliferative lesions include fibrocystic disease, inflammatory lesions such as breast abscess, and granulomatous mastitis. Malignant lesions are ductal carcinoma, lobular carcinoma, colloid carcinoma, mucinous carcinoma and medullary carcinoma. ${ }^{8}$

Numerous studies have been conducted with regard to breast lesions. Risk of breast cancer will increase in association with proliferative and atypical lesions. For early diagnosis, diagnostic methods such as mammography, ultrasonography, and fine-needle aspiration cytology are being progressively used nowadays. Evolution of more advances in imaging modalities and increased use of fine needle aspiration cytology have immensely helped in the preoperative assessment of lesions in the breast. Even though, in a majority of percentage of cases distinction between benign and malignant lesions still depends on histological assessment. Benign lesions are equally important as it has the potential to imitate cancers and not all the benign lesions are totally free of risks. Preservation of breast tissue is the treatment for most of the benign breast disease as far as possible in contrast to traumatizing disfiguring surgeries in breast carcinomas. Treatment for mass lesions in the breast depends on the root cause which may vary from simple pain medication to surgical removal of lump or mastectomy. For the diagnosis and categorization of breast lesions histopathology still plays an important role. ${ }^{9}$

The main purpose of the study is to analyse, highlight and to identify the histopathological spectrum and prevalence of breast lesions.

\section{METHODS}

A retrospective study was conducted in the department of Pathology, Azeezia Medical College, Kollam on 867 cases from 2018 to 2019. The sample size was taken based on the convenience of the study. All mastectomy specimens and wide local excision specimens which were received for histopathological examination suspected for neoplastic and non-neoplastic lesions of the breast during the study period were included in the study. The study was approved by Ethical Committee and informed consent was obtained. Women those who had been treated for malignancy earlier were excluded from the study.

Among the 867 specimens, majority of the specimens were those of lumpectomy specimens and a few specimens were mastectomy specimens. The clinical details and examination findings, magnetic resonance imaging (MRI), fine-needle aspiration cytology (FNAC), mammography findings, and other relevant information were acquired from the histopathology registration form. All the specimens of breast which were received in Pathology department in different forms such as excisional biopsy, lumpectomy and mastectomy were processed by standard protocol and formalin fixed paraffin embedded tissue sections stained with haematoxylin and eosin were studied and assessed. The histopathological features were noted, and the tumours were diagnosed on the basis of WHO classification. ${ }^{6}$

\section{Statistical Analysis}

Chi-square test was used to find association between spectrums of lesions. SPSS software was used for statistical analysis.

\section{RESULTS}

The ages of the cases ranged between 16 years to 60 years. The peak occurrence of the non-neoplastic lesions was found to be in the second and third decades, of which benign proliferative lesions were found to be in the age group 31-40 years. Unilateral lesions (91.7\%) were much more common than bilateral lesions in our study. Out of the 867 cases we received during the study period 766 were benign (88.3\%) of which the most common was fibro adenoma accounting for 496 (57\%) of all cases followed by fibroadenosis (16.26\%). Among the malignant cases the most common was invasive ductal carcinoma NOS accounting for 92 cases $(10.6 \%)$.

Fibro adenoma accounted for $496(57 \%)$ cases of all the benign breast lesions. Most of the cases were seen in 21-30 years succeeded by 11-20 years. Most of cases presented with unilateral breast lump. Grossly tumour masses ranged from $0.5 \mathrm{cms}$ to $6.5 \mathrm{cms}$ and in most of them, they showed slit like spaces on cut surface. Intracanalicular and pericanalicular pattern were seen histologically and, in some cases, both the patterns were identified in the same lesion.

We got 4 cases of giant fibro adenomas which additionally showed histological changes such as adenosis, cyst formation and apocrine change. Out of 766 benign breast lesions, fibrocystic disease were seen in 88 cases $(10 \%)$. Majority of the patients belonged in the age group of 41-50 years. Microscopically, they were characterized by overgrowth of both fibrous stroma and of epithelial elements which comprised of lobules and ducts, in varying proportions. In our study 4 cases were lactating adenoma. All the cases of lactating adenomas were seen around the age group of 21-30 years. One case of tubular adenoma was also there in our study. Macroscopically, the tumour measured around $3 \times 2 \mathrm{~cm}$ and on microscopy, the lesion was lined by benign epithelial cells and numerous closely packed uniform small tubules, with very less stroma. 
Of all benign lesions, benign Phyllodes tumour was seen in 5 cases in our study. Most of which were seen in the age range of 41-50 years. Grossly, the size of the tumour was around 5$15 \mathrm{~cm}$ in diameter and cut surface was showing many irregular nodules. Microscopically, these tumours showed stromal proliferation along with mitotic figures that were less than 2 3 per 10 high power fields. Among the 101 malignant lesions, 92 cases were of invasive ductal carcinoma NOS (10.6\%), 7 cases were of intraductal carcinoma (9\%), and one case each in medullary carcinoma and mucinous carcinoma, was seen. Among the malignant lesions of the breast, invasive ductal carcinoma NOS was the most common.

\begin{tabular}{|c|c|}
\hline Benign & Number of Cases \\
\hline Fibro adenoma & $496(57 \%)$ \\
\hline Fibroadenosis & $141(16.26 \%)$ \\
\hline Fibrocystic disease & $88(10 \%)$ \\
\hline Inflammatory lesion & $26(2.9 \%)$ \\
\hline Benign phyllodes & $5(0.5 \%)$ \\
\hline Ductal papilloma & $5(0.5 \%)$ \\
\hline Galactocele & $5(0.5 \%)$ \\
\hline \multicolumn{2}{|c|}{ Table 1. Benign Breast Lesions } \\
\hline
\end{tabular}

\begin{tabular}{|c|c|}
\hline Malignant & Number of Cases \\
\hline Invasive ductal carcinoma, NOS & $92(10.6 \%)$ \\
\hline Intraductal carcinoma & $7(9 \%)$ \\
\hline Mucinous carcinoma & $1(0.1 \%)$ \\
\hline Medullary carcinoma & $1(0.1 \%)$ \\
\hline \multicolumn{2}{|c|}{ Table 2. Malignant Breast Lesions } \\
\hline
\end{tabular}

\section{DISCUSSION}

The breast tissue is comprised of peculiar epithelium and stroma which has the capability of changing into benign or malignant lesions. There are about six to ten major duct systems in the human breast. Keratinizing squamous epithelium lines, the overlying skin of the breast which steeps into the nipple orifices which then promptly turns and continues to line the ducts as a double-layered cuboidal epithelium. The larger ducts then branch which finally lead to the formation of the terminal duct lobular unit. The ducts and the lobules are lined by two cell types and they are the luminal epithelial cells that overlay the epithelial cells ${ }^{10}$. Majority of the benign spectrum of lesions in the breast includes fibro adenomas, phyllodes tumour, mastitis, and breast abscess whereas the malignant spectrum of breast lesions includes ductal carcinoma, lobular carcinoma, tubular carcinoma, mucinous carcinoma, medullary carcinoma, papillary carcinoma, and metaplastic carcinoma. Breast lesions always show a female preponderance when compared to incidence in males, and the histopathological spectrum of breast lesions varies among different countries and ethnic group ${ }^{11}$. The common predisposing conditions for breast lesions include multiparty, low parity, low age at first childbirth, and late menopause, all these to only highlight the fact toward excessive circulating oestrogen. . $^{2,10}$

Occurrence of benign lesions of breast in our present study was $88.3 \%$ of all the breast lesions. These findings were comparable with the studies done by Hatim et al ${ }^{13}$ who had $80 \%$ of the cases and Rasheed et al ${ }^{14}$ who had $80.7 \%$ cases. The mean age in our study which is 33.63 years is found to be much lesser when compared to the study in the western literature where the mean age is found to be 54 years. Reported frequency of fibro adenoma in England is about $7.7 \%$ and in the USA it is about $8.5 \%{ }^{4}$ In the study, it is seen that benign lesions of the breast were more common which was about $83.4 \%$ in $\leq 40$ years age group, whereas malignant lesions of the breast were more common which was about $85.1 \%$ in $>40$ years age group, which correlates to the findings in the studies by Kumar ${ }^{7}$ and Reddy et al. ${ }^{4}$ In our study, the most common benign lesion is fibro adenoma 496 cases (57\%), followed by fibrocystic change $16 \%$ and carcinoma $11.7 \%$. Our findings were correlating with the findings of cases reported by Sangma et al, ${ }^{15}$ Hatim et al $^{14}$,Rasheed et al ${ }^{15}$ and Dayanand et al. 16

In our study the peak occurrence of fibro adenoma was seen in 21-30 years followed by 11-20 years. We had three cases $(2.8 \%)$ of complex fibro adenoma in our study along with which showed various morphological patterns like adenosis, cyst formation and apocrine change which was correlating with study done by Vilasini Patil et al. ${ }^{17}$ Geethamala K et al ${ }^{18}$ and Dupont et al $^{19}$ also reported $1.5 \%$ and $22 \%$ of complex fibro adenomas respectively and opined in the general population there is 3.1 times increased risk of developing invasive breast carcinoma from complex fibro adenoma when in comparison to women with fibro adenoma. Uncoordinated proliferation of the epithelial and stromal component leads to the development of fibro adenoma which mostly arise from the terminal duct lobular unit and due to the expansive growth of the lesion ${ }^{10}$ it creates a pseudo capsule and might involve a part of the surrounding tissues. The stromal element of fibro adenoma undergoes myxoid degeneration such as sclerosis, hyalinization, or calcification. The epithelial element of the fibro adenoma may present as proliferative or nonproliferative aspects of breast parenchyma which constitutes of apocrine metaplasia, ductal hyperplasia, sclerosing adenosis, and florid adenosis which is considered as complex. ${ }^{20,21}$

In the present study lactating adenoma accounted for $1.87 \%$ of cases which was comparable to that of studies by Pudale et $\mathrm{al}^{22}$. In our study the mean age of presentation of lactating adenoma was found to be 27 years. Only one case of tubular adenoma was seen in a 23-year-old female. Pudale et al and Vilasini et al also reported an incidence of lactating adenoma which was seen in patients belonging to the age group of 11-30 years. ${ }^{22,17}$ In our study inflammatory breast changes were seen in 26 specimens and these usually develop as a result of systemic or target organ-specific diseases and usually the secondary location site is breast. Of all benign inflammatory benign lesions, granulomatous mastitis accounted for 2 cases in the present study. Hatim et al ${ }^{13}$ and Vilasini et al $^{17}$ found an incidence of mastitis with most of the cases in between 31-40 years. In this study 4 cases were that of duct ectasia $(2.5 \%)$ which was found to be correlating with incidence of $2.77 \%$ cases reported by Rasheed et al. ${ }^{14}$ Duct ectasia is a condition in which there is an obstruction and associated inflammation of the lactiferous duct. Mammary duct ectasia usually presents with pain, swelling, nipple retraction, and bloody nipple discharge and due to this presentation, this can mimic as breast cancer and this lesion is usually considered as a premalignant lesion or as a precursor for malignancy. ${ }^{17}$

In our study the other benign lesions were phyllodes tumour and duct papilloma with an incidence of less than $1 \%$ each. Of all fibroepithelial breast diseases phyllodes tumour 
comprises for $2-3 \%$ and has a peak occurrence in the perimenopausal age group or can occur before 20 years of age. The pathognomonic pattern of this disease lesion is that it has marked intraductal growth of intralobular stroma with leaflike projections. Ductal papilloma usually presents with nipple secretion. ${ }^{10}$ In the current study, invasive ductal carcinoma NOS 92 cases $(10.6 \%)$ is the most common malignant breast lesion which is similar with that of the findings of study by Kumar. ${ }^{7}$ Due to its localized invasion, lymph node spread, and distant metastasis it has a high mortality rate. Invasive type carcinoma usually associated with poor prognosis. A screening process should be done in all the women of age $>20$ years as the peak age of the incidence of benign breast lesions was the 3 rd decade (21-30 years) and malignant lesions was in the $4^{\text {th }}$ decade, so that most of the breast disease can be diagnosed early and treated at the earliest. The knowledge regarding the risk of breast cancer should be spread across the globe ${ }^{10}$ by conducting more awareness programs amongst the public.

\section{CONCLUSIONS}

Benign breast disease is a heterogeneous group of disorders of breast in females and is more common than the malignant lesions. Histopathological examination still plays an important role in differentiating between benign and malignant lesions. In the present study, the most common benign breast lesion is fibroadenoma with an incidence of $57 \%$ and the most common malignant breast lesion is infiltrating ductal carcinoma with an incidence of $10.6 \%$. The optimal incidence of benign lesions of the breast is seen in the age group of 21-30 years, and the peak incidence of malignant lesions of the breast is seen in 41-50 years.

This study highlights the significance of identifying and treating benign breast lesions at an early stage and also differentiating benign breast lesions from in situ and invasive breast carcinomas. More importance should be given to assess and diagnose breast carcinoma by routine clinical, radiological, cytological and histological methods so that appropriate treatment modalities can be initiated. Proper breast cancer awareness study and screening programs should be conducted across women of all strata, so that basic training and motivation can be given to women so that they report to the doctors immediately once a lump is noticed. This can reduce the mortality and morbidity associated with breast tumours.

\section{REFERENCES}

[1] Desai M. Role of obstetrician and gynecologist in management of the breast lump. J Obstet Gynaecol India 2003;53:89-91.

[2] Sharkey FE, Craig Allred DC, Valente PT, et al. Andersons pathology. 10th edn. St. Louis: Mosby 1996: p. 2454-85.

[3] Klein S. Evaluation of palpable breast masses. Am Fam Physician 2005;71(9):1731-8.
[4] Moolamalla RM, Raghu K. Histopathological spectrum of neoplastic and non-neoplastic breast lesions-a two year study. Int J Sci Stud 2017;4(11):158-62.

[5] Nikumbh DB, Kanthikar SN, Suryawanshi KH, et al. Histopathological spectrum of unusual breast lesions - a seven year retrospective review. Indian Journal of Pathology and Oncology 2016;3(3):456-62.

[6] Ferlay J, Shin HR, Bray F, et al. Estimates of worldwide burden of cancer in 2008: GLOBOCAN 2008 Int J Cancer 2010;127(12):2893-917.

[7] Kumar R. A clinicopathologic study of breast lumps in Bhairahwa, Nepal. Asian Pac J Cancer Prev 2010;11(4):855-8.

[8] Kumar V, Abbas A, Fausto, et al. Pathologic basis of disease: the breast. $7^{\text {th }}$ edn. Philadelphia, PA: Elsevier 2017: p. 1119-54

[9] Akrami M, Mokhtari M, Tahmasebi S, et al. Surgical and clinical pathology of breast diseases. Ch. 3 . http://www.dx.doi. org/10.5772/52105.

[10] Yogalakshmi S, Kavitha M. A study of histopathological spectrum of breast lesions. Int J Sci Stud 2019;7(1):1-5.

[11] Mansoor I. Profile of female breast lesions in Saudi Arabia. J Pak Med Assoc 2001;51(7):243-7.

[12] Siddiqui MS, Kayani N, Gill MS, et al. Breast diseases: a histopathological analysis of 3279 cases at a tertiary care center in Pakistan. J Pak Med Assoc 2003;53(3):94-7.

[13] Hatim KS, Laxmikant NS, Mulla T. Patterns and prevalence of benign breast disease in Western India. Int J Res Med Sci 2017;5(2):684-8.

[14] Rasheed A, Sharma S, Mohsin-ul-Rasool, et al. A three year study of breast lesions in women aged 15-70 years in a tertiary care hospital. Sch J App Med Sci 2014;2(1B):1668.

[15] Sangma MBM, Panda K, Dasiah S. A clinico-pathological study on benign breast diseases. J Clin Diagn Res 2013;7(3):503-6.

[16] Dayanand V, Shashidhar HB, Sandya M, et al. Spectrum of breast neoplasms in females: a 10 years. Histopathological review in a tertiary care hospital. Int J Sci Stud 2015;3(2):79-84.

[17] Patil V, Khandelwal A, Kanchanmala G. et al. Histopathological spectrum of benign breast lesions. J Res Med Dent Sci 2017;5(4):9-14.

[18] Geethamala K, Vani BR, Murthy VS, et al. Fibro adenoma: a harbour of various histopathological changes. Clin Cancer Investig J 2015;4(2):183-7.

[19] Dupont WD, Parl FF, Hartmann WH, et al. Breast cancer risk associated with proliferative breast disease and atypical hyperplasia. Cancer 1993;71(4):1258-65.

[20] Sklair-Levy M, Sella T, Alweiss T, et al. Incidence and management of complex fibro adenomas. AJR Am J Roentgenol 2008;190(1):214-8.

[21] Kuijper A, Mommers EC, van der Wall E, et al. Histopathology of fibroadenoma of the breast. Am J Clin Pathol 2001;115(5):736-42.

[22] Pudale S, Tonape SD. A histopathological study of nonmalignant breast lesions. Int J Res Med Sci 2015;3(10):2672-6. 